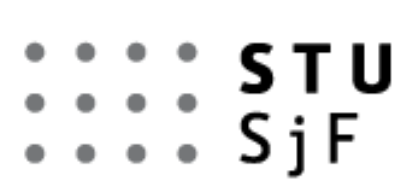

\title{
FSW NUMERICAL SIMULATION OF ALUMINIUM PLATES BY SYSWELD - PART I
}

\author{
JANČO Roland ${ }^{1}$, ÉCSI Ladislav ${ }^{1}$, ÉLESZTŐS Pavel $^{\mathbf{1}}$ \\ ${ }^{1}$ Slovak University of Technology in Bratislava, Faculty of Mechanical Engineering, \\ Institute of Applied Mechanics and Mechatronics, Nám. slobody 17, 81231 Bratislava, Slovakia, \\ e-mail:roland.janco@stuba.sk; ladislav.ecsi@stuba.sk; pavel.elesztos@stuba.sk
}

\begin{abstract}
Friction Stir Welding (FSW) is one of the most effective solid state joining processes and it has numerous potential applications in many industries. The simulation process can provide the evolution of physical quantities such as temperature, metallurgical phase proportions, stress and strain which can be easily measured during welding. The numerical modelling requires the modelling of a complex interaction between thermal, metallurgical and mechanical phenomena. The aim of this paper is to describe the thermal-fluid simulation of FSW using the finite element method. In the theoretical part of the paper heating is provided by the material flow and contact condition between the tool and the welded material. The thermal-fluid results from the numerical simulation for aluminium alloy using SYSWELD are also presented in this paper.
\end{abstract}

KEYWORDS: Friction Stir Welding (FSW); aluminium alloy; Finite element method; thermo-fluid model

\section{Introduction}

Friction stir welding (FSW) is a relatively new joining technology which was developed and patented in 1991 by The Welding Institute (TWI), in the United Kingdom [1]. This is a solid state welding process providing good quality of butt and lap joints. The FSW process has been proved to be ideal for creating high quality welds in a number of materials including those which are extremely difficult to weld by conventional fusion welding. A schematic of friction stir welding process is illustrated in Fig. 1.

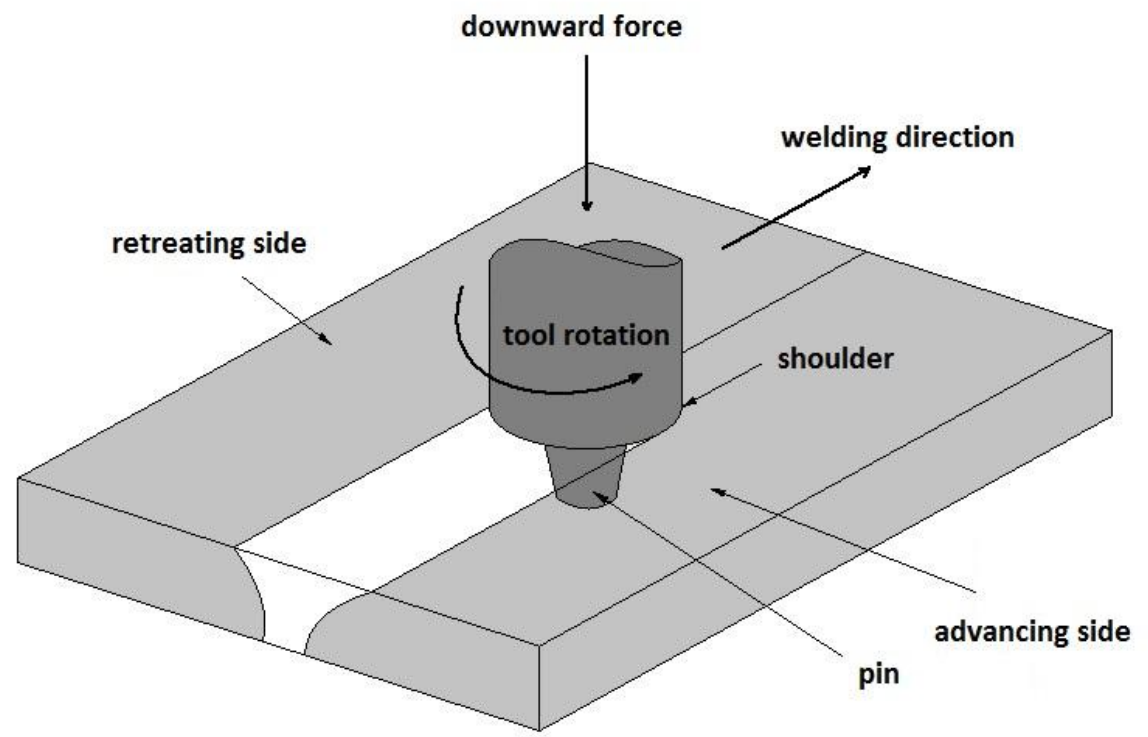

Fig. 1. Schematic diagram of FSW 
The welding zone is completely isolated from the atmosphere during the welding process. The advantages of this type of welding are minimized formations of voids in the welding zone, so that welding defects and large distortions commonly associated with fusion welding are minimized or avoided. This welding technique is extensively applied to the aerospace, automobile and shipbuilding industries $[5,6,7,8,9,10]$.

\section{Theoretical background}

In FSW, the heat generation takes place mainly under the shoulder, leading to a variable thermal gradient in the through-thickness direction of the plate. The general three dimensional partial differential equation of heat conduction in solid can be represented by

$$
\frac{\partial(\rho c T)}{\partial t}=\frac{\partial}{\partial t}\left(k_{x} \frac{\partial T}{\partial x}\right)+\frac{\partial}{\partial t}\left(k_{y} \frac{\partial T}{\partial y}\right)+\frac{\partial}{\partial t}\left(k_{z} \frac{\partial T}{\partial z}\right)+\frac{q_{o}}{V},
$$

where $\rho c$ is the volume heat capacity; $x, y$ and $z$ are the space coordinates; $k_{x}, k_{y}$ and $k_{z}$ are thermal conductivity, $\mathrm{T}$ temperature, $\mathrm{t}$ time and $q_{o} / V$ is the source term.

\section{2. $1 \quad$ Heat generation during FSW}

For the ideal case considered in Fig.1, the torque required to rotate a circular shaft relative to the plate surface under the action of an axial load is given by [2]

$$
M=\int_{0}^{M_{R}} d M=\int_{0}^{R} \mu P(r) 2 \pi r^{2} d r=\frac{2}{3} \mu \pi P R^{3},
$$

where $M$ is the interfacial torque, $\mu$ is the friction coefficient, $R$ is the surface radius, and $P(r)$ is the pressure distribution across the interface. If all the shearing work at the interface is converted into frictional heat, the average heat input per area and time becomes [2]

$$
q_{0}=\int_{0}^{M_{R}} \omega d M=\int_{0}^{R} \omega 2 \pi \mu P r^{2} d r,
$$

where $q_{o}$ is the net power (in Watts) and $\omega$ is the angular velocity (in $\mathrm{rad} / \mathrm{s}$ ). Angular velocity can by expressed in term of the rotation speed N. By substituting $\omega=2 \pi N$ into Eq. (3), we get

$$
q_{0}=\int_{0}^{R} 4 \pi^{2} \mu P N r^{2} d r=\frac{4}{3} \pi^{2} \mu P N R^{3} .
$$

From Eq. (4), it is obvious that the heat input depends both on the applied rotational speed and the shoulder radius, leading to a non-uniform heat generation during welding.

\subsection{Heat generation in SYSWELD by FSW modulus}

In SYSWELD by FSW modulus is effective viscosity _ defined from Newton-Hoff law used to model the hot forming process [3]:

$$
\mu=K(T) \cdot(\sqrt{3} \cdot D)^{m(T)-1},
$$

where $K$ and $m$ are the consistency and the sensibility of material, and $D$ is the equivalent strain rate

$$
D=\sqrt{\frac{2}{3} \overline{\bar{D}}: \overline{\bar{D}}}
$$


The friction between the toll and the workpiece is of Neumann boundary condition. Heat flux density modelled between tool and material contact is [3]

$$
q=\beta \cdot \vec{\tau} \cdot \Delta \vec{v},
$$

where $\beta$ is the proportion of the heat dissipated thought viscous dissipation $\bar{\tau}$. $\Delta \bar{v}$ and received by the sheets. All thermal boundary conditions are in the Fig. 2.

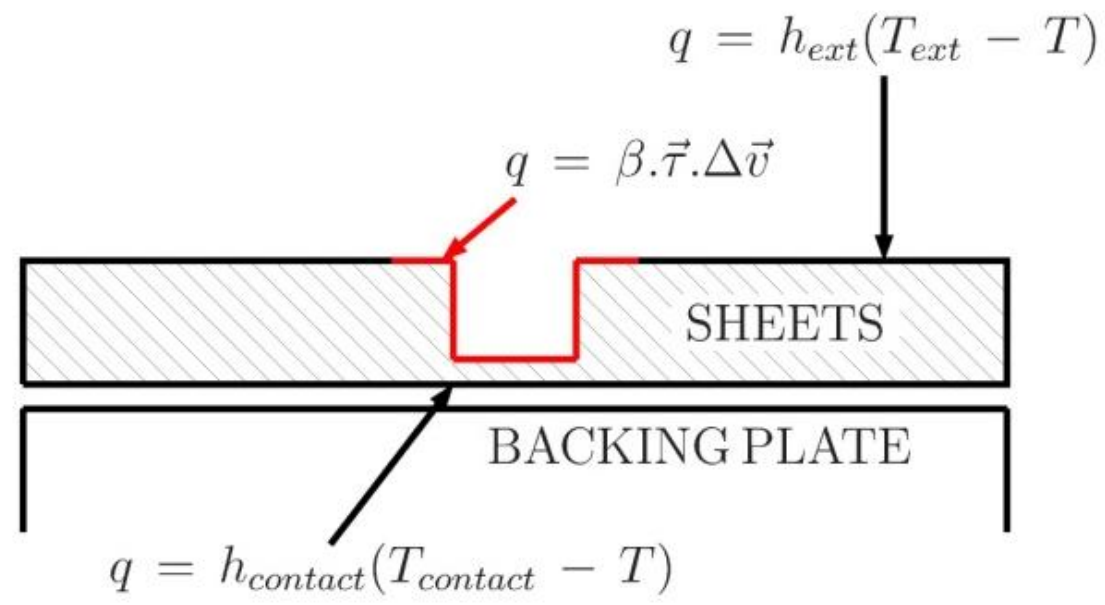

Fig. 2. Thermal boundary conditions

\section{Numerical solution by SYSWELD}

An example is presented in this section. The thermal properties for sheet and backing plate are described in Tab. 1, the friction coefficient is 0.238 , linear welding velocity is $1.67 \mathrm{~mm} / \mathrm{s}$, tool rotation velocity 41.89 rad. $\mathrm{s}^{-1}$, room temperature $15{ }^{\circ} \mathrm{C}$ and heat exchange coefficient for convection 19 $\mathrm{W} /\left(\mathrm{m}^{2} . \mathrm{K}\right)$. A finite element model of sheet and backing plate is presented in Fig. 3. A finite element model of tool is shown in Fig. 4. The results of the solution from software SYSWELD ${ }^{\circledR}$ are presented in fig. 5 and 6.

Table 1. Material properties of sheet and backing plate.

\begin{tabular}{|c|c|c|c|c|c|c|c|c|c|c|c|c|}
\hline \multirow[b]{2}{*}{$\begin{array}{l}\mathbf{T} \\
{\left[{ }^{\circ} \mathrm{C}\right]}\end{array}$} & \multicolumn{6}{|c|}{ Sheet (Aluminium alloy) } & \multicolumn{6}{|c|}{ Backing Plate (Steel) } \\
\hline & $k$ & {$\left[\frac{\mathrm{W}}{\mathrm{mm}{ }^{\circ} \mathrm{C}}\right]$} & $\rho .10^{-6}$ & $\frac{\mathrm{kg}}{\mathrm{mm}^{3}}$ & $c$ & $\frac{\mathrm{J}}{\mathrm{kg}^{\circ} \mathrm{C}}$ & $k$ & {$\left[\frac{\mathrm{W}}{\mathrm{mm}^{\circ} \mathrm{C}}\right]$} & $\rho .10^{-6}$ & {$\left[\frac{\mathrm{kg}}{\mathrm{mm}^{3}}\right]$} & $c$ & $\frac{\mathrm{J}}{\mathrm{kg}{ }^{\circ} \mathrm{C}}$ \\
\hline 20 & & 0.130 & 2. & & & 898.0 & & 0.068 & 78 & & & 430 \\
\hline 120 & & & 2. & & & 951.0 & & & & & & 500 \\
\hline 220 & & & 2. & & & 1003.0 & & 0.059 & 78 & & & 550 \\
\hline 320 & & & 2. & & & 1055.0 & & & & & & 580 \\
\hline 420 & & & 2. & & & 1108.0 & & 0.047 & 77 & & & 610 \\
\hline 500 & & & & & & & & & & & & 650 \\
\hline 587 & & 0.170 & 2. & & & 1195.0 & & & & & & \\
\hline 600 & & & & & & & & 0.036 & 76 & & & 710 \\
\hline 644 & & & 2. & & & 1200.0 & & & & & & \\
\hline 700 & & & & & & & & & 76 & 13 & & 790 \\
\hline 800 & & & & & & & & 0.029 & & & & 865 \\
\hline 900 & & & & & & & & 0.027 & & & & 565 \\
\hline 1450 & & & & & & & & 0.033 & & & & \\
\hline 1600 & & & & & & & & & & $\overline{90}$ & & 630 \\
\hline 2447 & & & & & & 1300.0 & & & & & & 707 \\
\hline
\end{tabular}




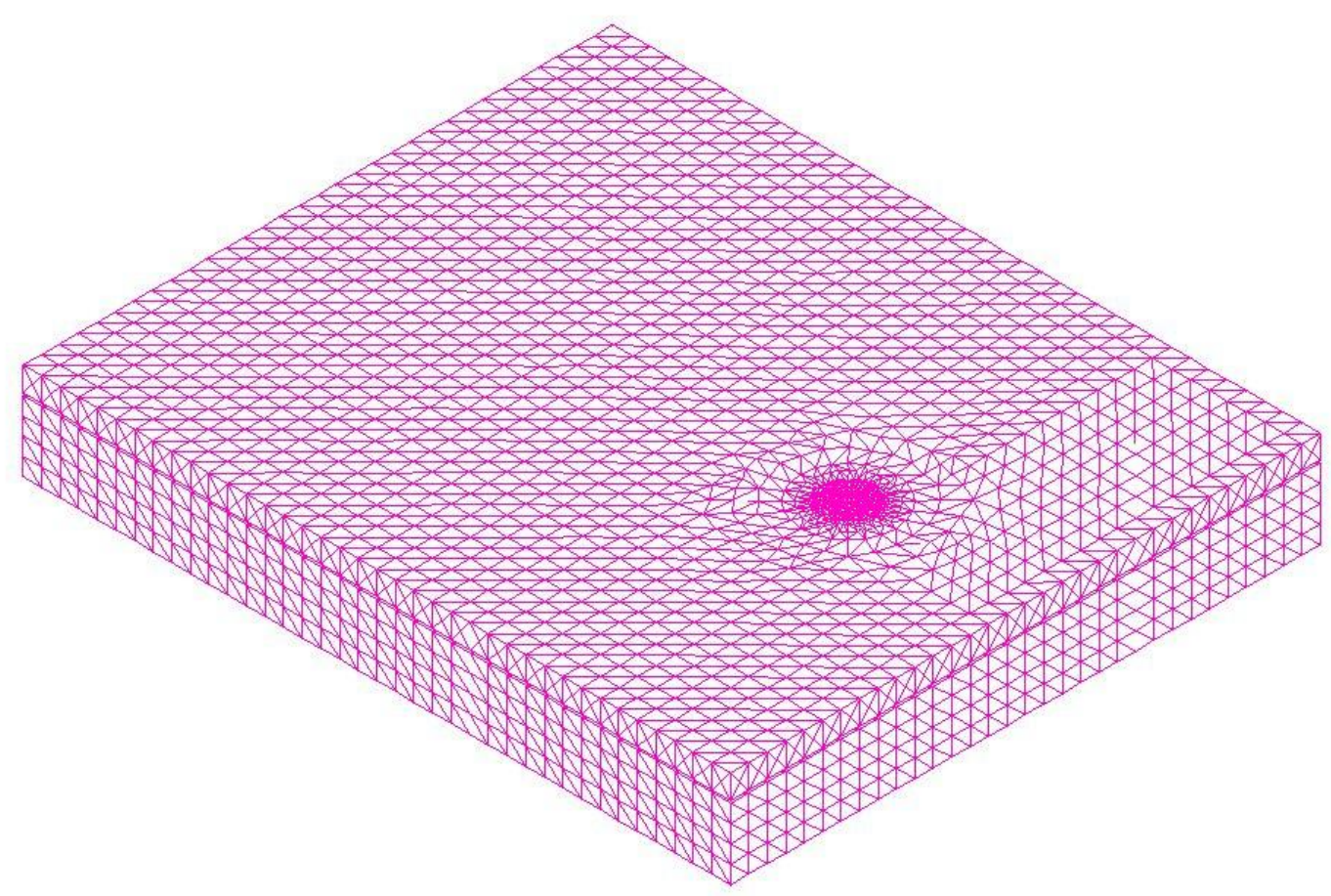

Fig. 3. FEM model of sheet and backing plate

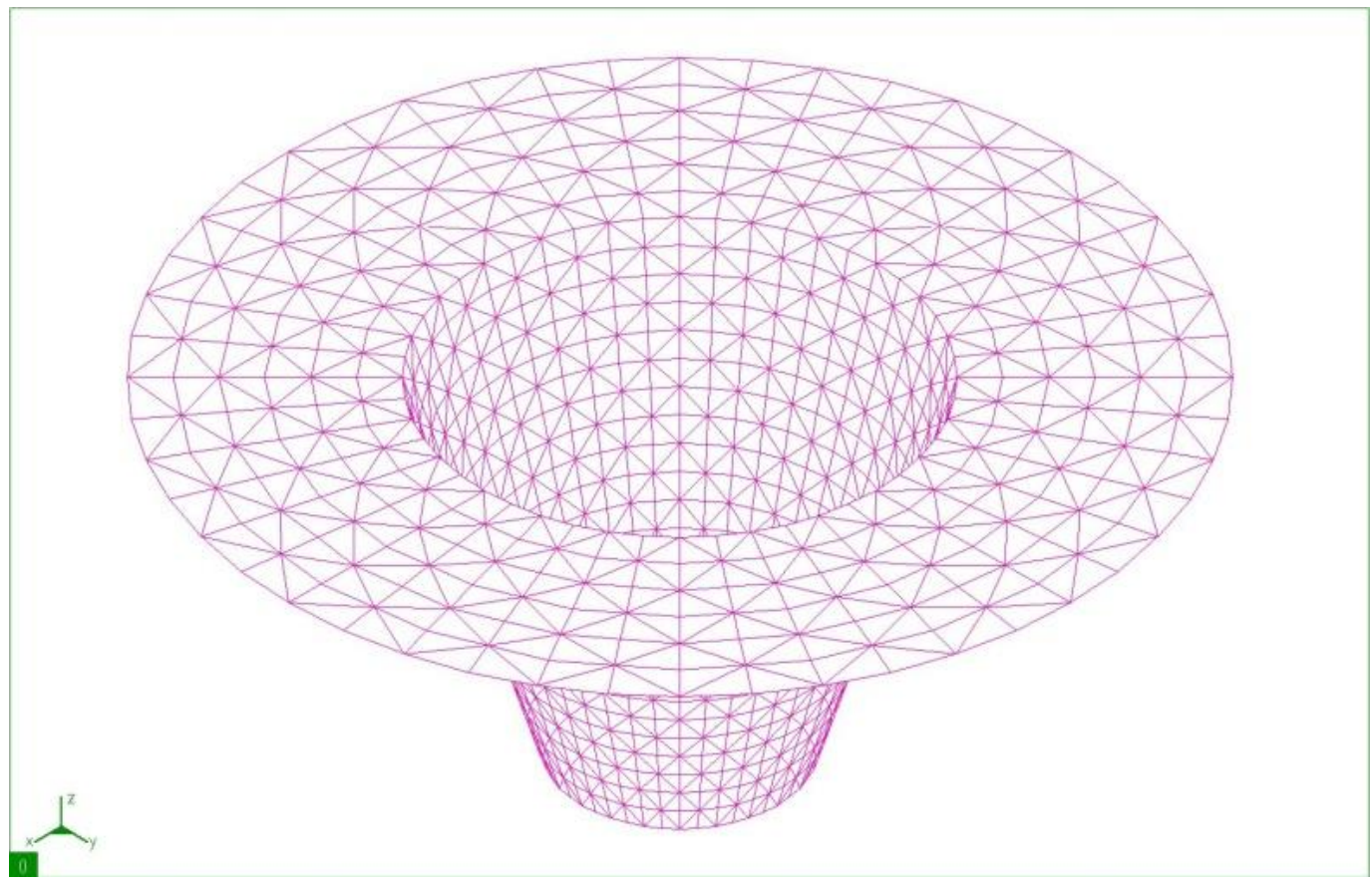

Fig. 4. FEM model of tool 


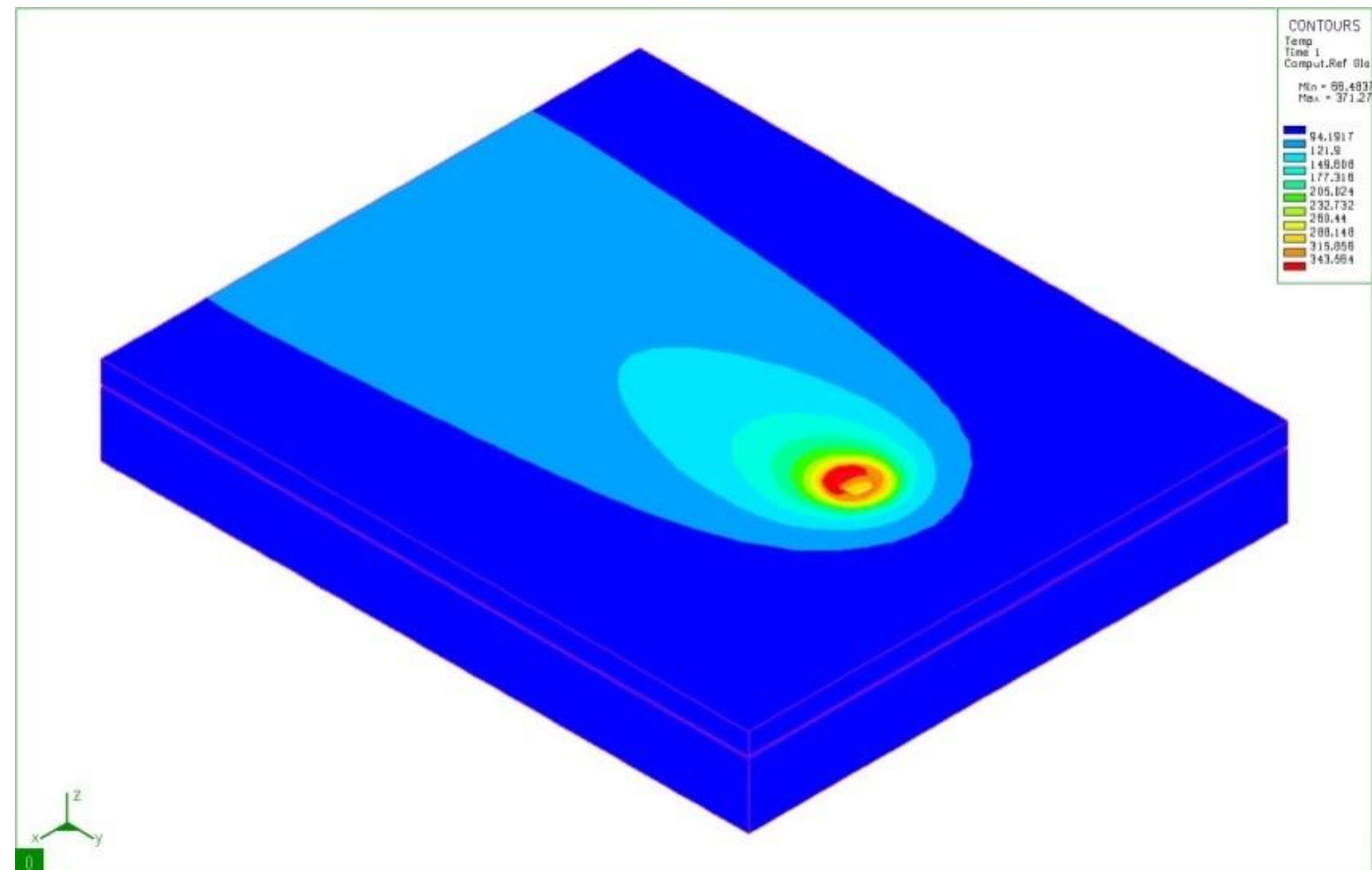

Fig. 5. Temperature profile

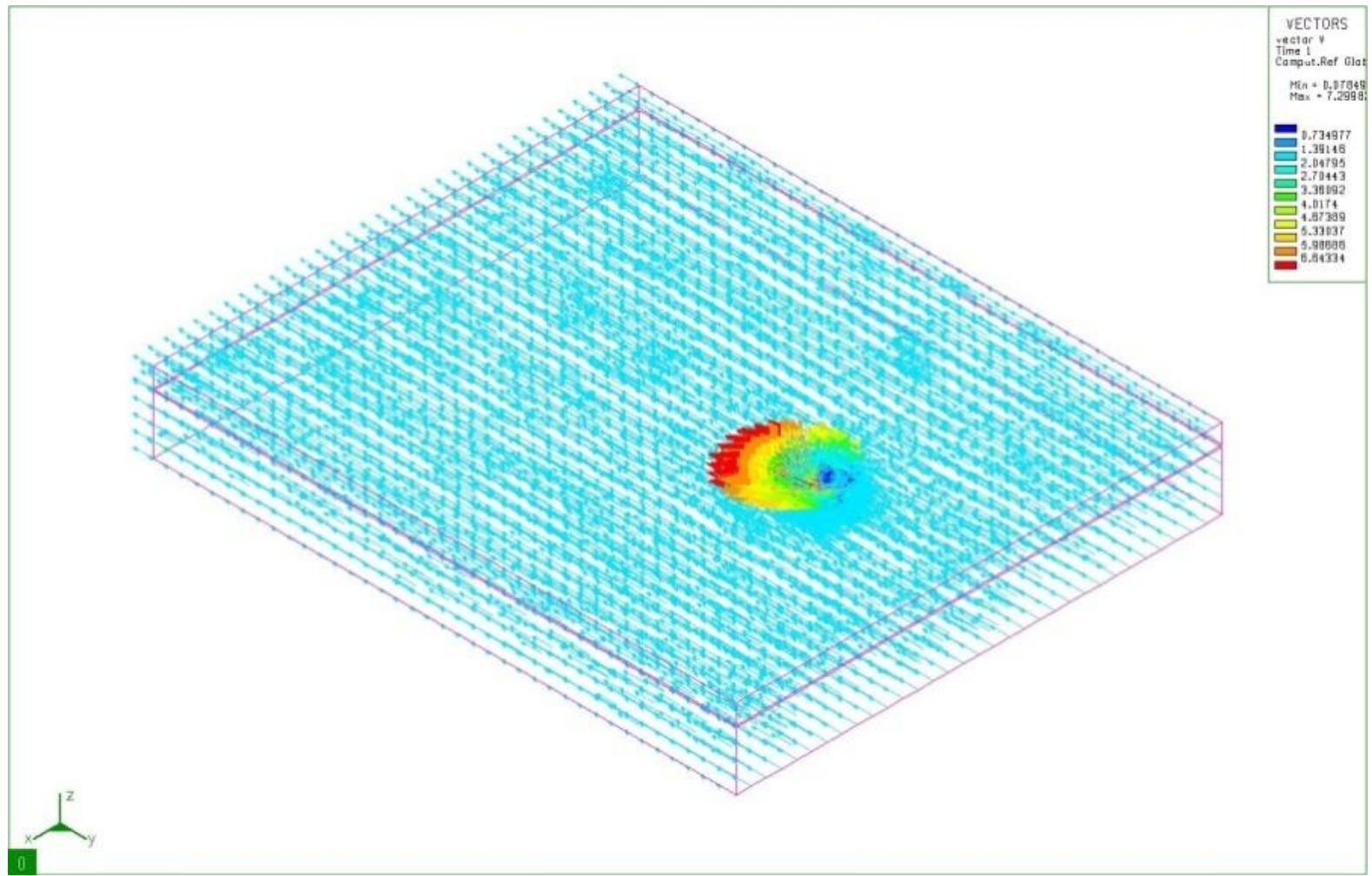

Fig. 6. Velocity field

\section{Conclusion}

In this paper, a 3D finite element procedure is presented to model the thermo-fluid flow in FSW for the stationary step in SYSWELD ${ }^{\circledR}$. For the computation of the example proposed in section 3, the mesh is composed of 13457 nodes and 69111 elements. In Fig. 5 the temperature field from SYSWELD ${ }^{\circledR}$ is presented. The numerical results were compared with experimental measurement by

Volume 66, No. 1, (2016) 
thermo-camera and thermocouples. In section 2 is presented theoretical background for solution of FSW. The results have proved, as it was expected, that high temperature gradients are created. As a result, a further study ought to be carried out to investigate how considering the $2^{\text {nd }}$ sound phenomenon [4] in the mathematical model affects the temperature field.

\section{Acknowledgements}

This publication is the result of the project implementation: Research of friction stir welding (FSW) application as an alternative to melting welding methods no. 26240220031 supported by the Research \& Development Operational Programme funded by the ERDF.

\section{References}

[1] CHEN, C.M., KOVACEVIC, R.: Finite element modeling of friction stir welding thermal and thermomechanical analysis, International Journal of Machine Tools \& Manufacture, Vol. 43, 2003, pp. 1319-1326, ISSN 0890-6955, http://www.sciencedirect.com/science/article/pii/ S0890 695503001585

[2] FRIGAARD, Ø., GRONG, Ø., MIDLING, O.T.: A Process Model for Friction Stir Welding of Age Hardening Aluminium Alloys, Metallurgical and Materials Transactions A, Vol. 32A, 2001, pp. 1189-1200

[3] FEULVARCH, E., ROBIN, V., BOITOUT, F., BERGHEAU, J.M.: 3D Modelling of Thermo fluid Flow in Friction Stir Welding Including Metallurgical and Mechanical Consequences, Mathematical modelling of weld phenomena, 8, 2007, pp. 1-24, ISSN 9783902465696, http://books.google.sk/books?id=7auqPgAACAAJ

[4] SZEKERES, A.: Equation System of Thermoelasticity Using the Modified Law of Thermal Conductivity, Periodica Polytechnica, 24 No. 3, pp. 253-261

[5] TREBUŇA, F., ŠIMČÁK, F., BOCKO, J.: Failure analysis of storage tank, In: Engineering Failure Analysis, Vol. 16, No. 1, 2009, pp. 26-38, ISSN 1350-6307

[6] BOCKO, J.: Prehl'ad metód reanalýzy konštrukcií, In: Strojnícky časopis - Journal of Mechanical Engineering, Vol. 43, No. 3, 1992, pp. 268-279.

[7] MUSIL, M.: Localization and quantification of breathing crack. In Journal of Dynamic Systems Measurement and Control-Transactions of the ASME. Vol. 128, No. 2, 2006, pp. 458-462, ISSN 0022-0434

[8] ÚRADNÍČEK, J., MUSIL, M.: Study of adaptive control algorithm using hysteretic magneto-rheological damper model in 1/4 car suspension. In Strojnícky časopis Journal of Mechanical Engineering, Vol. 59, No. 4, 2008, pp.1-13, ISSN 0039-2472.

[9] JÁNOŠÍK, L', BUKOVECZKY, J., GULAN, L.: Use of load spectra in the design process of simplified tests of building machines. In Strojnicky časopis - Journal of Mechanical Engineering, Vol. 59, No. 3, 2008, pp. 163-174, ISSN 0039-2472.

[10] BUKOVECZKY, J., GULAN, L., SCHMIDTOVÁ, C.: Definition of size range of mobile working machines demonstrated on example of hydraulic excavators. In Scientific Proceedings Faculty of Mechanical Engineering STU in Bratislava, Vol. 21, 2013, pp. 33-38, ISSN 1338-1954 